\title{
KECEMASAN IBU HAMIL DAN IBU NIFAS PADA MASA PANDEMI COVID-19 DI KECAMATAN BATURRADEN
}

\author{
Diki Retno Yuliani, Fajaria Nur Aini \\ Poltekkes Kemenkes Semarang \\ email: dikiretnoyuliani@gmail.com
}

\begin{abstract}
COVID-19 has an impact on people's well-being, which can be a psychological problem for pregnant women and postpartum mothers, one of them is anxiety. The purpose of this study was to find out the description of anxiety of pregnant women and postpartum mothers during the COVID-19 pandemic. Research design was descriptive research. The samples were 28 pregnant women and 23 postpartum mothers in Baturraden Sub-district with cluster sampling techniques. The instrument used is The perinatal anxiety screening scale (PASS). The results were pregnant women and postpartum mothers in Baturraden Sub-district, during the COVID-19 pandemic, the majority experienced anxiety on a mild-medium scale.
\end{abstract}

Keywords: Anxiety, Pregnant Woman, Postpartum, COVID-19 Pandemic

\begin{abstract}
ABSTRAK
COVID-19 berdampak pada kesejahteraan masyarakat, hal tersebut dapat menjadi permasalahan psikologis bagi ibu hamil dan ibu nifas, salah satunya kecemasan. Tujuan studi ini untuk mengetahui gambaran kecemasan ibu hamil dan ibu nifas di masa pandemi COVID-19. Desain penelitian adalah penelitian deskriptif. Sampel adalah 28 ibu hamil dan 23 ibu nifas di kecamatan Baturraden dengan teknik cluster sampling. Intrumen yang digunakan adalah the perinatal anxiety screening scale (PASS). Hasil yang diperoleh adalah ibu hamil dan ibu nifas di Kecmatan Baturraden, pada masa pandemi COVID-19, mayoritas mengalami kecemasan dengan skala ringan-sedang.
\end{abstract}

Kata Kunci: kecemasan; ibu hamil; ibu bersalin; pandemi COVID-19

\section{Pendahuluan}

Faktor-faktor yang dapat mencetuskan stres pada ibu hamil diantaranya rasa ketidaknyamanan selama kehamilan, pekerjaan, kekhawatiran pada proses persalinan, perubahan hormon serta kondisi bayi. Hasil studi melaporkan bahwa berdasarkan keterangan yang diperoleh dari ibu hamil dengan stres, berbagai macam masalah yang mereka alami meliputi permasalahan ekonomi, keluarga, pekerjaan, serta rasa cemas terhadap kehamilan maupun persalinan (Taslim, Kundre and Masi, 2016).

COVID-19 (Coronavirus disease 2019) telah ditetapkan Pemerintah sebagai bencana nasional non alam. COVID-19 di Indonesia telah menimbulkan banyak korban jiwa, kerugian material yang besar serta berdampak pada seluruh aspek kehidupan masyarakat, meliputi aspek sosial, ekonomi dan kesejahteraan masyarakat (Presiden RI, 2020).

Pandemi COVID-19 menyebabkan banyak pembatasan hampir ke semua layanan rutin, baik secara akses maupun kualitas, termasuk pembatasan dalam pelayanan kesehatan maternal dan neonatal, seperti adanya pengurangan frekuensi pemeriksaan kehamilan dan penundaan kelas ibu hamil (Direktorat Kesehatan Keluarga, 2020). 
Kondisi-kondisi tersebut dapat menjadikan permasalahan secara psikologis bagi ibu hamil dan ibu nifas, yang dapat menimbulkan kecemasan. Sebuah studi melaporkan bahwa gejala depresif dan kecemasan pada wanita hamil setelah deklarasi pandemi COVID-19 lebih tinggi dibandingkan sebelum deklarasi COVID-19, termasuk kecenderungan ingin melukai diri sendiri (Wu et al., 2020). Hal tersebut dapat menyebabkan kondisi bahaya selama kehamilan, sehingga mempengaruhi kondisi ibu dan janin (Durankuş and Aksu, 2020). Studi yang melaporkan kecemasan terkait COVID-19 tidak hanya pada ibu hamil saja, namun juga pada ibu nifas (Nanjundaswamy et al., 2020).

Angka kejadian COVID-19 di Provinsi Jawa Tengah, berdasarkan data yang diakses tanggal 01 - 14 Oktober 2020 menempati urutan ke 2 - 3 secara Nasional (Gugus Tugas COVID-19 Nasional, 2020). Tujuan dari penelitian ini adalah untuk mengetahui tingkat kecemasan ibu hamil dan ibu nifas di Kecamatan Baturraden, salah satu Kecamatan di Kabupaten Banyumas yang merupakan wilayah Provinsi Jawa Tengah.

\section{Metode Penelitian}

Desain penelitian yang digunakan adalah penelitian deskriptif. Populasi target dalam penelitian ini adalah ibu hamil dan ibu nifas di Kabupaten Banyumas, populasi terjangkau adalah ibu hamil dan ibu nifas di Kecamatan Baturraden Kabupaten Banyumas. Sampel Penelitian ini adalah 30 ibu hamil dan 23 ibu nifas di Wilayah Kecamatan Baturraden yang terdiri dari 12 desa. Selama proses penelitian, ada dua responden ibu hamil yang dropout, satu ibu keguguran dan satu ibu mengundurkan diri terkait dengan perangkat yang digunakan, sehingga jumlah ibu hamil yang menjadi responden adalah 28 orang.

Teknik pengambilan sampel yang digunakan adalah cluster, yaitu untuk ibu hamil diambil dari dua Desa di wilayah kerja Puskesmas Baturraden I dan dua Desa di wilayah kerja Puskesmas Baturraden II dengan jumlah ibu hamil relatif banyak. Sedangkan untuk ibu nifas diambil dari empat Desa di wilayah kerja Puskesmas
Baturraden I dan empat Desa di wilayah kerja Puskesmas Baturraden II dengan jumlah ibu nifas relatif banyak.

Kriterian inklusi dalam penelitian ini adalah ibu hamil dan ibu nifas yang bersedia mengikuti penelitian secara daring (online), kriteria eksklusi adalah ibu hamil dan ibu nifas yang tidak memiliki Hanphone/android atau memiliki handphone namun tidak memiliki Whatsapp dan tidak bisa akses google form. Semua responden yang memenuhi kriteria inklusi dan eksklusi dijadikan responden.

Penelitian dilaksanakan pada bulan Oktober 2020. Data dikumpulkan melalui pengisian google form biodata responden dan kuesioner kecemasan PASS (The perinatal anxiety screening scale). Pada minggu pertama responden diminta untuk mengisi form persetujuan menjadi responden dan mengisi biodata. Pada minggu ke dua responden diminta untuk mengisi kuesioner kecemasan.

PASS adalah instrumen self-report yang dirancang untuk skrining masalah kecemasan pada wanita hamil dan postpartum (kurang dari 1 tahun). PASS terdiri dari 31 item pertanyaan yang terbukti valid dan reliabel. Empat domain yang diukur adalah Kekhawatiran Berlebihan dan Ketakutan Khusus, Perfeksionisme, Kontrol dan Trauma, Kecemasan Sosial serta Kecemasan Akut dan Pengaturan. Total skor 0-93, dengan klasifikasi 0-20 "tidak ada gejala"; 21-41 "kecemasan ringan-sedang" dan 42-93 "kecemasan berat" (Somerville et al., 2014).

Analisis data menggunakan distribusi frekuensi karakteristik responden dan kecemasan pada ibu hamil dan ibu nifas. Ethical clerence diajukan pada komisi etik penelitian Poltekkes Kemenkes Semarang melalui http://sim-epk.keppkn.kemkes.go.id/ dan disetujui tanggal 20 Oktober 2020.

\section{Hasil dan Pembahasan}

Karakteristik responden dapat dilihat pada tabel 1, yaitu mayoritas responden memiliki usia 20-35 tahun, pendidikan SMA, pekerjaan ibu rumah tangga, gravida 1 dan tidak pernah abortus. 
Tabel 1. Karakteristik Responden

\begin{tabular}{lcccc}
\hline Parameter & \multicolumn{4}{c}{ Frekuensi } \\
& Ibu & Hamil & lbu & Nifas \\
& $\mathrm{N}$ & $\%$ & $\mathrm{~N}$ & $\%$ \\
\hline Usia & & & & \\
< 20 tahun & 0 & 0 & 2 & 9 \\
$20-35$ tahun & 24 & 86 & 20 & 87 \\
$>35-40$ th & 4 & 14 & 1 & 4 \\
$\quad$ Total & 28 & 100 & 23 & 100 \\
Pendidikan & & & & \\
SD & 3 & 11 & 1 & 4 \\
SMP & 7 & 25 & 6 & 26 \\
SMA/SMK & 16 & 57 & 13 & 57 \\
PT & 2 & 7 & 3 & 13 \\
Total & 28 & 100 & 23 & 100 \\
Pekerjaan & & & & \\
PNS & 0 & 0 & 1 & 4 \\
Karyawan & 3 & 11 & 2 & 9 \\
Swasta & 1 & 4 & 0 & 0 \\
lbu & 22 & 78 & 19 & 83 \\
tangga & & & & \\
Lain-lain & 2 & 7 & 1 & 4 \\
Total & 28 & 100 & 23 & 100 \\
Gravida & & & & \\
1 & 11 & 39 & 8 & 35 \\
2 & 9 & 32 & 8 & 35 \\
3 & 5 & 18 & 5 & 22 \\
4 & 2 & 7 & 1 & 4 \\
4 & 0 & 0 & 1 & 4 \\
5 & 1 & 4 & 0 & 0 \\
6 & 28 & 100 & 23 & 100 \\
Total & & & & \\
Abortus & 25 & 89 & 18 & 78 \\
Tidak pernah & 2 & 7 & 4 & 18 \\
1 kali & 0 & 0 & 1 & 4 \\
2 kali & 4 & 0 & 0 \\
3 kali & 100 & 23 & 100 \\
Total & & & & \\
\hline & 28 &
\end{tabular}

Tabel 2. Distribusi frekuensi kecemasan pada ibu hamil dan ibu nifas

\begin{tabular}{lcccc}
\hline \multirow{2}{*}{ Kecemasan } & \multicolumn{4}{c}{ Kecemasan } \\
& lbu hamil & \multicolumn{1}{c}{ lbu nifas } \\
& $N$ & $\%$ & $N$ & $\%$ \\
\hline Tidak bergejala & 7 & 25 & 3 & 13 \\
Ringan-sedang & 18 & 64 & 16 & 70 \\
Berat & 3 & 11 & 4 & 17 \\
Total & 28 & 100 & 23 & 100 \\
\hline
\end{tabular}

Hasil penelitian menunjukkan bahwa, $75 \%$ ibu hamil di Kecamatan Baturraden mengalami kecemasan dari skala ringansedang sampai skala berat, dengan mayoritas tingkat kecemasan ibu hamil adalah kategori ringan-sedang (tabel 2). Hasil tersebut menggambarkan bahwa, mayoritas ibu hamil di Kecamatan Baturraden mengalami kecemasan. Hal ini sesuai dengan studi yang melaporkan bahwa ibu hamil yang mengalami kecemasan saat pandemi COVID-19 mencapai 63-68 \%. Data menggambarkan bahwa $40 \%$ Dokter Obstetri Ginekologi pernah dihubungi oleh lebih dari sepuluh ibu hamil, karena kecemasan terkait COVID-19 (Nanjundaswamy et al., 2020)

Kecemasan pada ibu hamil saat masa pandemi COVID-19 perlu menjadi perhatian. Sebuah studi melaporkan bahwa pada masa pandemi COVID-19 ibu hamil yang mengalami kecemasan berat mencapai 57,5 \%, dan ada hubungan antara kecemasan ibu dengan kesiapan ibu hamil trimester 3 untuk menghadapi persalinan di masa pandemi COVID-19 (Angesti, 2020). Hal tersebut menunjukkan bahwa kecemasan ibu hamil, termasuk pada masa pandemi COVID-19 perlu penanganan secara tepat agar tidak mengganggu kesiapan menghadapi persalinan sehingga persalinan dapat berjalan dengan aman dan selamat.

Hasil penelitian juga menunjukkan bahwa $87 \%$ ibu nifas mengalami kecemasan dengan mayoritas kecemasan kategori ringan-sedang (table 2), hasil tersebut menggambarkan bahwa mayoritas ibu nifas di Kecamatan Baturraden mengalami kecemasan pada masa pandemi COVID-19. Hal ini sesuai dengan studi yang melaporkan bahwa skor subscale EPDS (Edinburgh Postnatal Depression scale) pada ibu nifas (immediate postpartum) menunjukkan bahwa nilai rata-rata untuk anhedonia, kecemasan, dan depresi semuanya lebih tinggi pada kelompok ibu nifas saat COVID-19 dibandingkan dengan kelompok ibu nifas satu tahun sebelumnya (Zanardo et al., 2020).

Kecemasan pada ibu nifas, juga harus menjadi perhatian. Sebuah studi melaporkan bahwa 59,5 \% ibu nifas mengalami kecemasan terkait pandemi COVID-19 dan kecemasan terkait COVID19 tersebut berpengaruh terhadap pengeluaran ASI (Tambaru, Hilda and Theresia, 2020). Studi lain melaporkan bahwa kekhawatiran ibu nifas tentang risiko terpapar COVID-19, masa karantina dan langkah-langkah yang diadopsi selama pandemi COVID-19, dapat berdampak 
buruk pada pemikiran dan emosi ibu baru serta memperburuk gejala depresi (Zanardo et al., 2020).

Sebuah studi mempublikasikan beberapa hal yang sering atau sangat sering menyebabkan kecemasan dan kekhawatiran terkait COVID-19 pada ibu hamil dan ibu nifas adalah kunjungan ke rumah sakit untuk periksa kehamilan (72,65\%), metode perlindungan COVID-19 $(60,17 \%)$, pesan di media sosial $(52,14 \%)$, keselamatan bayi dari infeksi setelah dilahirkan (52,14), pengaruh COVID-19 pada janin $(45,76 \%)$ dan hasil kehamilan $(44,92)$ serta keamanan untuk menyusui $(44,44 \%)$ (Nanjundaswamy et al., 2020).

Secara umum, kecemasan pada ibu hamil dan ibu nifas dapat berdampak pada kesehatan ibu dan janin atau bayi. Dengan adanya pandemi COVID-19 dapat meningkatkan insiden atau tingkatan kecemasan pada ibu hamil dan ibu nifas, sehingga permasalahan tersebut memerlukan penanganan lebih lanjut, untuk mengurangi dampak negatif pada kesejahteraan ibu dan janin atau bayi. Rekomendasi kami adalah, dalam setiap kunjungan antenatal pada masa pandemi, baik secara tatap muka maupun secara daring, pengkajian pada psikologis ibu hamil dan ibu nifas dapat dilaksanakan dengan lebih optimal, sehingga jika terdeteksi menderita permasalahan psikologis seperti kecemasan, segera dapat diberikan penatalaksanaan lebih lanjut.

Keterbatasan dalam penelitian ini adalah pemilihan sampel ibu nifas secara cluster tidak mencukupi jumlah sampel yang diinginkan yaitu 30. Dalam penelitian ini tidak ada konflik kepentingan.

\section{Kesimpulan}

Kesimpulan dari studi ini adalah ibu hamil dan ibu nifas di Kecamatan Baturraden, pada masa pandemi COVID-19 mayoritas mengalami kecemasan dengan skala ringan-sedang.

\section{Ucapan Terima Kasih}

Ucapan terima kasih kami sampaikan kepada Kepala Dinas Kesehatan Kabupaten Banyumas, Kepala Puskesmas
Baturraden I, Kepala Puskesmas Baturraden II Dan jajarannya yang telah memberikan ijin dalam pelaksanaan penelitian serta Poltekkes Kemenkes Semarang yang telah memberikan pembiayaan penelitian.

\section{Daftar Pustaka}

Angesti, E. P. W. (2020) 'Hubungan Tingkat Kecemasan Dan Pengetahuan lbu Hamil Trimester 3 Dengan Kesiapan Menghadapi Persalinan Di Masa Pandemi COVID-19 Di Puskesmas Benowo Dan Tenggilis'. Universitas Airlangga.

Direktorat Kesehatan Keluarga (2020) 'Pedoman Bagi Ibu Hamil, Ibu Nifas, dan Bayi Baru Lahir Di Era Pandemi COVID-19', pp. 9-12. Available at: http://www.kesga.kemkes.go.id/imag es/pedoman/Pedoman bagi lbu Hamil, Bersalin, Nifas dan BBL di Era Pandemi COVID 19.pdf.

Durankuş, F. and Aksu, E. (2020) 'Effects of the COVID-19 pandemic on anxiety and depressive symptoms in pregnant women: a preliminary study', The Journal of Maternal-Fetal \& Neonatal Medicine. Taylor \& Francis, pp. 1-7.

Gugus Tugas COVID-19 Nasional (2020) Peta Sebaran COVID-19 Di Indonesia. Available at: covid19.go.id (Accessed: 9 November 2020).

Nanjundaswamy, M. H. et al. (2020) 'COVID-19-related anxiety and concerns expressed by pregnant and postpartum women-a survey among obstetricians', Archives of women's mental health. Springer, pp. 1-4.

Presiden RI (2020) Keputusan Presiden Republik Indonesia No 7 Tahun 2020 Tentang Gugus Tugas Percepatan Penananan COVID-19. Indonesia.

Somerville, S. et al. (2014) 'The perinatal anxiety screening scale: development and preliminary validation', Archives 
of women's mental health. Springer, 17(5), pp. 443-454.

Tambaru, R., Hilda, H. and Theresia, F. I. (2020) 'Pengaruh Kecemasan Pandemi COVID-19 Terhadap Pengeluaran Asi lbu Post Partum Di Bidan Praktik Mandiri Hj. Rusmawati Di Muara Badak'. Skripsi STr Kebidanan, Poltekkes Kemenkes Kaltim.

Taslim, R. W. R., Kundre, R. and Masi, G. (2016) 'Hubungan pola makan dan stres dengan kejadian hipertensi grade 1 dan 2 pada ibu hamil di wilayah kerja Puskesmas Kamonji Kecamatan Palu Barat', JURNAL KEPERAWATAN, 4(1).
Wu, Y. et al. (2020) 'Perinatal depressive and anxiety symptoms of pregnant women along with COVID-19 outbreak in China', American Journal of Obstetrics and Gynecology. Elsevier.

Zanardo, V. et al. (2020) 'Psychological impact of COVID-19 quarantine measures in northeastern Italy on mothers in the immediate postpartum period', International Journal of Gynecology \& Obstetrics. Wiley Online Library. 